\title{
Rosalía de Castro agonista. Diálogos protagonista y antagonista con la ciudad de Santiago de Compostela
}

\author{
Lucía GARCÍA VEGA \\ lugarvega@gmail.com
}

Recibido: 5 de septiembre de 2011

Aceptado: 26 de septiembre de 2011

\section{Resumen}

La prestigiosa escritora Rosalía de Castro (1837-1885), además de nacer y de ser bautizada en Santiago de Compostela, residió en este espacio urbano en diferentes momentos de su vida. Asimismo algunos de sus principales acontecimientos biográficos ocurrieron en esta ciudad gallega. Y puesto que las descripciones, las alusiones directas e indirectas a este sitio son de aparición frecuente, parece lícito considerar que se trata de un punto geográfico determinista, tanto en su itinerario biográfico como también en su trayectoria literaria, a la vez que de necesaria y vigente prospección crítica.

Palabras clave: Rosalía de Castro, Posromanticismo, Santiago de Compostela, espacio literario urbano, literatura gallega.

Title: Rosalia de Castro agonist. Protagonist and antagonist dialogues with the city of Santiago de Compostela.

\section{Abstract}

The renowned writer Rosalía de Castro (1837-1885), in addition to birth and be baptized in Santiago de Compostela, lived in this urban space at different times of her life. Also some of the main biographical events occurred in this Galician city. And since the descriptions, the direct and indirect allusions to this site are frequently occurring, it seems legitimate to consider that it is a geographic location, borth in her biographical itinerary as well as her literary career, while the necessary and current critical exploration.

Keywords: Rosalia de Castro, Post-Romanticism, Santiago de Compostela, literary urban space, Galician literature.

\section{Índice}

1. Introducción

2. Visión general de Santiago de Compostela

3. Visión protagonista y central. Rosalía y Compostella

3.1. Recinto de la Catedral

3.2. Eje Fonseca-Hospital Real-San Martiño Pinario

4. Visión antagonista y periférica. Rosalía y sus refugios limítrofes

5. Conclusión

\section{Introducción}

La ilación continua que existió entre la escritora Rosalía de Castro y Santiago de Compostela permite preconcebir una hoja de ruta 
interpretativa sobre el significado que esta ciudad gallega obtiene en varias de sus obras literarias.

Como es lógico pensar, la variable biográfica puede llegar a tener mucho más peso del que tradicionalmente se ha considerado, a lo que habría que sumarle la importancia de tener en cuenta el parámetro espacial urbano -enfoque que, salvo excepciones (vid. García Vega 2010a), sigue siendo poco común, por no decir que inexistente- como catalizador analítico que posibilite un avance crítico sobre la recíproca adaptación o inadaptación de la escritora a su ciudad natal y su reflejo en la literatura.

Esta ciudad universalmente conocida resultó ser el escenario espacial de grandes alegrías como fueron los nacimientos de cuatro de sus siete hijos, Alejandra (1859-1938), Aura (1868-1942), Adriano (1875-1876) y Valentina (1877), aunque también Santiago de Compostela se tornó en dramático lugar sepulcral para la eximia escritora, al fallecer aquí su madre, Teresa de Castro y Abadía (†1862), y sus dos últimos hijos, Adriano y Valentina.

Es quizás esta oposición dual básica entre la vida y la muerte la que podría estar desarrollando un papel de mayor responsabilidad a la hora de interpretar la variabilidad descriptiva sobre el lugar compostelano. Por ello el objetivo que nos marcamos en este artículo es llegar a conocer algo más acerca de las condiciones que determinan la perspectiva, principal y opuesta, en el diálogo mantenido entre la escritora y la ciudad compostelana.

\section{Visión general de Santiago de Compostela}

Una primera cuestión que causa sorpresa es la relativa a la ausencia total del topónimo normativo correspondiente a lo largo de los textos literarios de Rosalía de Castro y en los que bien se recoge la forma Santiago bien se refleja el nombre Compostela, sin conocerse aun las razones de la presencia o la ausencia de una u otra forma en su producción.

En cualquier caso es innegable la trascendencia que tiene Santiago de Compostela tanto en la lírica como en la prosa, lugar aludido de manera explícita en Follas novas (1880), En las orillas del Sar (1884), en las novelas El primer loco (1881) y "Ruinas. Desdichas de tres vidas ejemplares" (1866), y en el artículo de costumbres "Padrón y las inundaciones" (1881).

Si se ahonda un poco más en el estado de la cuestión, entonces resulta oportuno presentar ya algún rasgo sobre el concepto que la escritora parece que tuvo de Santiago de Compostela y el modo en que se filtra y se registra en varios de sus textos escritos. Bien es cierto que las referencias a la ciudad compostelana entrarían dentro de la definición factible de ser descripciones autobiográficas, aunque aquí utilizaremos un eufemismo menos comprometedor, el relativo a 
comentar las visiones de una prosista y una poeta de la experiencia compostelana.

En el texto "Padrón y las inundaciones"1 se muestra de forma inequívoca la percepción que la articulista tiene de Compostela ya desde las primeras líneas. El nombre de lugar va asociado a dos percepciones sensitivas, una al sonido de las campanas y otra a la mala climatología, factores que desencadenan el regreso de los recuerdos a la mente de la escritora, a la vez que son elementos necesarios para la creación del exordio y que justifican esta parte del texto:

Huyendo al eterno clamoreo de las campanas de Compostela, cuyos ecos, mezclados a los bramidos de las tempestades invernales, parecen perseguir con saña los ánimos entristecidos, y deseando alejarnos de aquellas montañas y verdes praderas, cuyo melancólico aspecto tiene el don de recrudecer todas las pasadas amarguras. (Castro 1993: 2, 631)

Más adelante, la narradora vuelve a incidir en el aspecto de la poca simpatía que le despierta Compostela y establece una comparación entre dos de los lugares más vinculados a su biografía, por lo tanto, la ciudad compostelana y el lugar Padrón²:

Pero en cambio, desde que he vuelto aquí sentí de nuevo un reposo relativo; sentí que circulaba más libremente por mis estrechas venas la espesa sangre que me atrofiaba el corazón y que aquellas nubes, tan densas iay! que me abrumaban el alma, desaparecían de mi atmósfera y quedaban allá lejos, cerniéndose sobre la brumosa Compostela, en unión de algunos aborrecidos recuerdos que se resistían a abandonarme, como el buitre hambriento a dejar los restos del cadáver en que se ha cebado. (Castro 1993: 2, 635)

Una percepción bastante semejante de este lugar, en lo que a la climatología se refiere, se encuentra en el poema "O encanto da pedra chan" de Follas novas. En esta ocasión la poeta no duda en plasmar una adjetivación sobre la ciudad compostelana totalmente antitética a los conceptos de lo luminoso y de lo alegre: "i espesa nube de trebóns preñada, / partindo da sombrisa Compostela, / que no confín lexano se trasvía / cal se trasvé na tarde moribunda / a raia sin fulgor da noite fría" (Castro 1993: 2, 394).

\footnotetext{
${ }^{1}$ Hay varias versiones de este artículo costumbrista. Para esta cuestión, vid. García Vega (2002: 37-42).

2 Rosalía de Castro escribió el artículo de costumbres "Padrón y las inundaciones" en el lugar de Lestrobe, que por aquellas fechas pertenecía al ayuntamiento de Padrón, provincia de A Coruña. En la actualidad Lestrobe está integrado en el ayuntamiento de Dodro, provincia de A Coruña.
} 
Por otra parte, en el poema titulado "Santa Escolástica" de En las orillas del Sar, la voz lírica presenta una descripción general de la ciudad compostelana como "Soplo mortal creyérase que había / dejado el mundo sin piedad desierto, / convirtiendo en sepulcro a Compostela" (Castro 1993: 2, 514), continuando unos versos más adelante con la declaración contundente "-iCementerio de vivos! murmuraba / yo al cruzar por las plazas silenciosas / que otros días de gloria nos recuerdan" (Castro 1993: 2, 514).

La relación de escasa armonía entre la voz lírica y el espacio urbano de la vieja Compostela parece afianzarse todavía más a través de alusiones directas del tipo "Que en la santa ciudad, grave y vetusta, / no hay rumores que turben importunos / la paz ansiada de la apacible siesta" (Castro 1993: 2, 514), o también mediante la presentación de preguntas retóricas que encierran dudas, como por ejemplo: "¿Es verdad que hubo aquí nombres famosos, / guerreros indomables, grandes almas? / ¿Dónde hoy su raza varonil alienta?" (Castro 1993: 2, 514).

Es en la tercera parte del poema "Santa Escolástica" cuando la poeta precisa sobre Compostela que se trata de una "Ciudad extraña, hermosa y fea a un tiempo, / a un tiempo apetecida y detestada, cual ser que nos atrae y nos desdeña" (Castro 1993: 2, 516).

Por lo tanto, estaríamos ante algo de mayor calado que una mera abstracción o una visión estereotipada sobre el significado urbano compostelano para la escritora. Más bien habría que situarse en un preciso punto del plano interpretativo desde el que certificar que el distrito vetusto de Compostela parece simbolizar una dimensión espacial de la incompatibilidad. La poeta es el nexo entre la afinidad y la antipatía declaradas en diferentes momentos, sujeto que, de forma simultánea, mantiene alejado al lector de los motivos que podrían explicar toda o parte de esta alternancia.

Ahora bien, esta escasa atracción por la ciudad de Compostela podría atribuirse, en un primer momento, a las propias circunstancias en las que se desarrolló una parte de la biografía documentada de la escritora en este lugar. De tal forma, rebasada la década de los ochenta -nos referimos, por supuesto, al siglo XIX-, Rosalía de Castro había tenido que pasar por las dramáticas experiencias de dar sepultura a su madre y, desgraciadamente, también a dos hijos de corta edad, aspectos que justificarían en buena medida esta relación de poca armonía entre la voz lírica y el espacio urbano.

Sin embargo, si nos movemos retrospectivamente en la biografía de la escritora, encontramos una impresión de Compostela muy similar, y que quizás debiera ser interpretada con una esmerada atención, puesto que forma parte de los escasos escritos epistolares que se conservan. Así, Rosalía de Castro expresaba en una carta enviada a su marido el 16 de diciembre de 1861 que en "Santiago hace un frío espantoso", que "jamás he visto tanta soledad, tanta 
tristeza, un cielo más pálido" y que "por ahora me encuentro aquí en extremo descontenta. Santiago no es ciudad; es un sepulcro" (Castro 1993: 2, 601-602). Parece, pues, que esa sensación de poco agrado se mantuvo a lo largo del tiempo ${ }^{3}$, independientemente de la vivencia de algún que otro episodio fatídico como hemos señalado.

Todo lo reflejado hasta el momento estaría encaminándonos a una conclusión clara sobre el significado que, en mayor o en menor proporción, parece tener el distrito compostelano para la escritora. De tal forma, el trayecto seguido a este respecto nos situaría en una dimensión interpretativa y en un nivel conceptual de evidente calificación, es decir, que Santiago de Compostela se configura como una geografía de no preferencia.

$Y$, en general, el espacio urbano de Compostela bien podría definirse como el antónimo locativo a lo que la tradición literaria ha ido modelando como el tópico poético del locus amoenus, es decir, sería el anti-tópico del lugar perfecto y totalmente alejado del concepto de paisaje ideal.

No obstante, conviene puntualizar que este espacio compostelano no predilecto habría que delimitarlo al área urbana de lo que otrora fue villae y que se corresponde con la ciudad vieja, teniendo en la Catedral su símbolo más notorio, como veremos a continuación.

\section{Visión protagonista y central. Rosalía y Compostella}

Dentro de la jerarquización espacial que parece existir en el concepto de Santiago de Compostela y que la escritora parece asumir y reiterar, consideramos que la Compostella antigua tiende a adquirir una textura conceptual de micro espacio que se opone totalmente al conjunto de lugares compostelanos situados fuera del perímetro urbano más antiguo, estos últimos formando un dominio espacial caracterizado por la fascinación provocada por la naturaleza que incorpora las arquitecturas religiosas de tipo monacal, como veremos en su momento.

Una descripción que se ajusta bastante a la idea de lo que puede llegar a significar el dominio vetusto es la que le otorga la calidad de espacio central y que nació "como el árbol, y fue su germen el Sepulcro Apostólico, alimentada por la sangre de los obispos, reyes y peregrinos que siglo a siglo levantaron las piedras" (Torrente Ballester 1990: 60).

\footnotetext{
${ }^{3}$ Nótese que, además de la semántica idéntica, la sintaxis es casi exacta en la carta de 1861 y en los versos del poema "Santa Escolástica" de En las orillas del Sar ya aludidos (Castro 1993: 2, 514).
} 


\subsection{Recinto de la Catedral}

De este espacio religioso, entre otros, se despide la voz lírica en el poema "iAdiós!" de Follas novas: "Os mesmos verdes campos, as mesmas torres pardas / da catedral severa, ollando as lontananzas" (Castro 1993: 2, 289). La rigidez de esta estructura arquitectónica, la exigüidad de la naturaleza alrededor de ella, la imagen pétrea y el hieratismo de la construcción parecen ser algunas de las características que condicionan su percepción de este lugar y que la escritora no duda en identificar con grave, serio, severo.

En el poema titulado "Amigos vellos" de Follas novas, la poeta se sitúa dentro de la arquitectura religiosa, "Cando antre as naves tristes e frías / de alto mural, / cal elas fría, cal elas triste" (Castro 1993: 2, 308), y vive el espacio manifestando su deseo de convertirse en piedra. Se presenta, por tanto, la necesidad de no sufrir y de adoptar la forma lítica para no sentir ni miedo a la vida, "que dá tormentos" (Castro 1993: 2, 309), ni miedo a la muerte, "que espanto dá" (Castro 1993: 2, 309).

En este sentido, la propia naturaleza de la piedra estaría facilitando la clave para interpretar estos versos, teniendo en cuenta que el mundo mineral se opone por definición al mundo biológico, a la vida como tal, por lo tanto la voz lírica estaría buscando la forma de dejar de estar atormentada: "Quén fora pedra, quén fora santo / dos que alí hai" (Castro 1993: 2, 308).

Ya al final del texto, la poeta se sirve de otro de los grandes tópicos literarios, el tempus fugit, para expresar la incomodidad que le causa ser consciente del discurrir del tiempo, ansiando poseer la naturaleza perdurable de la Catedral y que contrasta con su esencia humana, es decir, efímera: "I as pedras quedan... e cando eu morra, / ti, Catedral, / ti, parda mole, pesada e triste, / icando eu non sea, ti inda serás!" (Castro 1993: 2, 309).

También, Rosalía de Castro le dedica a este espacio emblemático el poema "Na Catedral" de Follas novas, a través del que el lector parece estar asistiendo a una visita guiada poetizada por las cavidades del templo. Como peregrina medieval, la poeta permanece delante de las figuras de piedra que forman el Pórtico de la Gloria ${ }^{4}$ y se pregunta si "¿Estarán vivos?" (Castro 1993: 2, 292), realizando un ejercicio de visión retrospectiva desde el propio espacio del interior de la Catedral. Este contraste cronotópico, muy utilizado

\footnotetext{
${ }^{4}$ Se trata del conjunto escultórico de la fachada románica de la Catedral y al que se accede por la famosa plaza del Obradoiro. El artífice de esta joya arquitectónica fue el Maestro Mateo (ca. 1150-ca. 1200-1217?), según reza la inscripción del arco central que está dividida en dos partes por el parteluz: "Anno ab Incarnatione Domini MCLXXXVIII, Era MCCXXVI, die Kalendarum Aprilis, super liminaria principalium portalium Ecclesiae Beati Jacobi sunt collocata per Magistrum Mathaeum, qui a fundamentis ipsorum portalium gessit magisterium".
} 
en todo el poemario, vuelve a manifestarse en la esperanza pasada y en la infelicidad presente, en un desdoblamiento del yo que fue y del yo que es: "Santos do ceo, / ¿saberán eles que son a mesma / daqueles tempos?... / Pero xa orfa, pero enloitada, pero insensibre cal eles mesmos" (Castro 1993: 2, 293).

Muy en relación con lo anterior estaría la tendencia que tiene la escritora compostelana a aludir a las arquitecturas románicas, cuestión que nos estaría reconduciendo a la Edad Media. Si bien es cierto que el Pórtico de la Gloria sería paradigmático en este sentido, no es menos verdad que hay una presencia alta de huellas medievales y de tiempos pasados a lo largo de las obras literarias de Rosalía de Castro, bien en las menciones a los espacios -palacios, ruinas arquitectónicas, torres defensivas-, bien en las alusiones a los tipos humanos -frailes, caballeros, condes, duques-, bien en las referencias a las leyendas de esta época y, sobre todo, el poso de la lírica trovadoresca que existe en el poemario Cantares gallegos (1863).

De tal manera, al principio del poema "Na Catedral" aparece proyectada la radiografía de las élites sociales medievales, al presentar los poderes hegemónicos que resultaban ser la monarquía y la jerarquía eclesiástica: "i os arcebispos nos seus sepulcros, / reises e reinas con gran sosego / na paz dos mármores tranquilos dormen" (Castro 1993: 2, 291). En consecuencia, semeja oportuno considerar a este respecto que el yo subjetivo de Follas novas estaría mostrando un residuo sólido de medievalismo a través de la búsqueda de evasión del tiempo.

También en el mismo poema habría que reflexionar sobre la importancia que tiene la mención a la capilla de la Soledad ${ }^{5}$, espacio que le inspira a la poeta algunos de los versos más intimistas. Ya desde el propio nombre de esta virgen se puede intuir, en amplia dimensión, uno de los sentimientos intimistas más enraizados en la génesis y el desarrollo del poemario Follas novas. La voz lírica busca sentirse acompañada en la esfera de su soledad, "para mi madre deixei cariños, / para os meus fillos miles de beixos, / polos verdugos do meu esprito / recei... e funme, pois tiña medo" (Castro 1993: 2, 294), aunque al final de los versos llega a sentirse todavía más desamparada al comprender que la única compañía hallada es la misma soledad.

Este episodio lírico presenta toda una actuación monologada, motivada por la necesidad que tiene la poeta de sentirse cerca de sus

\footnotetext{
${ }^{5}$ Está ubicada al lado derecho de la capilla de la Corticela. La devoción a la Virgen de la Soledad está muy arraigada entre los compostelanos, y prueba de ello son la capilla aludida y también la existencia de una pila bautismal que sirve como depósito de limosnas, situada en uno de los pilares derechos de la nave central de la Catedral.
} 
seres queridos y que ya no están, por lo que busca atenuar el dolor provocado por estas ausencias. Es así como el sentido nominal de esta Virgen de la Soledad, y no otra, representaría el acercamiento momentáneo a un sentir pretérito, por lo que mencionar a aquellos que ya no están cerca sería el reflejo pasajero en el metafórico espejo de la felicidad de otra época. Recordar a su madre y a sus hijos en presencia de la Soledad, en la recreación imaginativa de un ser solitario a imagen y semejanza de ella, parece posibilitar la recuperación de un yo, o una parte, que se fue al mismo tiempo que sus familiares más cercanos. $Y$ el final de esta situación quedaría completado en los últimos versos, al anochecer, cuando los rayos del sol se ocultan detrás del compostelano monte Pedroso, en una visión simultánea al momento en que aparece su presente doliente, al tomar conciencia de la realidad y sentir miedo, cuando el sol ya no lanza serenos rayos por las vidrieras de la Soledad.

Por otro lado, y como parte indisoluble del significado de la Catedral, habría que tener en cuenta la importancia de la mención a la campana Berenguela ${ }^{6}$ y a la que se alude, de manera implícita, en varios textos literarios de Rosalía de Castro. De esta forma, en la novela Flavio (1861) se describe el espacio de la Catedral de un modo muy semejante al comentado:

Cuando el pobre viajero pasó ante la vieja y poética catedral, las grandes campanas doblaban tristemente, y sus sonidos lastimeros parecían gemir a través de las nieblas que envolvían torres, cimborrios, balaustradas atrevidas y de graciosas labores. [...]

Flavio entró en la iglesia; las desiertas naves parecían agrandarse hacia el fondo; las gruesas pilastras, las sencillas arcadas del arte primitivo, se levantaban severas y tristes; las sombras que las columnas proyectaban se tendían inmóviles, igual que negros gigantes, sobre el suelo de mármol; todo era silencio y tristeza. (Castro 1993: 1, 343-344)

De manera análoga, en la novela El primer loco se proyecta una idea similar sobre la lasitud que puede llegar a provocar la rutina, en este caso, de los mismos sonidos en el espacio compostelano:

Esta ciudad de las lluvias y de la estéril inmovilidad en donde parece que el tiempo detiene su eterna marcha para escuchar cómo las gotas de lluvia resuenan al caer sobre el embaldosado de granito de

\footnotetext{
${ }^{6}$ Estrenada el 24 de julio de 1729 , se hizo al pie de la Catedral, en la plaza de la Quintana y en donde se instaló un horno de leña para la fundición del bronce. El maestro campanero responsable de esta obra fue Pedro de Güesmes. Durante mucho tiempo existió la creencia relativa a que esta campana podía escucharse a mucha distancia, casi obrándose el milagro. La función más práctica que tuvo en otros tiempos fue la de marcar con sus tañidos el inicio y el final de las tareas cotidianas del rural próximo a Santiago de Compostela.
} 
sus calles, mientras las campanas de la catedral tocan por la mañana al alba, al coro por la tarde, siempre del mismo modo, monótonos siempre. (Castro 1993: 2, 754)

Continuando con los escritos en prosa, en el artículo de costumbres "El Domingo de Ramos" (1881) se reitera la misma sensación que le causa a la escritora este espacio:

Suelen grabarse tales recuerdos en cuantos vieron la luz y se criaron en alguna mediana ciudad de provincias, de esas en donde las torres de gótica o románica catedral con sus altas agujas indican desde muy lejos al forastero que las visita el punto en donde los edificios que la rodean se levanta severa y majestuosa la casa de Dios, y en la cual las campanas lanzan al viento sus vibraciones. (Castro 1993: 2, 665)

Todo parece indicar, por tanto, que el espacio de la Catedral se aleja bastante del concepto literario del locus amoenus, lo que estaría acentuando, más si cabe, la innegable no predilección por el espacio más antiguo compostelano y que tiene en la Catedral su mejor ejemplo.

Asimismo no deja de causar asombro en el investigador el conocimiento de una noticia que recientemente hemos exhumado. Ya fallecida Rosalía de Castro surgió la idea en Santiago de Compostela, entre intelectuales y admiradores de su obra, de levantar en el Pórtico de la Gloria un mausoleo en honor a su figura, idea que el destino quiso que no se llevase a la práctica, cuestión de la que se hico eco la prensa madrileña, según informamos a continuación:

Encuentra favorable acogida en Santiago la idea de erigir en el Pórtico de la Gloria de la Catedral compostelana el mausoleo que ha de recordar á las futuras generaciones la existencia de la ilustre poetisa y escritora Rosalía Castro de Murguía. Tratándose de un monumento regional, no hay gallego que no acoja con entusiasmo el pensamiento y colme de aplausos al prelado y cabildo compostelano, cuyos nombres irán unidos á la erección del monumento, para gloria de Galicia. (La Época 1888)

\subsection{Eje Fonseca-Hospital Real-San Martiño Pinario}

Estos tres espacios dentro de la ciudad vetusta compostelana constituyen la genuina expresión lírica del itinerario llevado a cabo por algunas de sus calles más emblemáticas y que la poeta realiza una tarde de abril, tal y como informa el primer verso del poema "Santa Escolástica" de En las orillas del Sar.

A pesar de que en los versos iniciales no hay ningún registro espacial explícito, la textura y el cromatismo líricos evidencian la atmósfera ambiental compostelana: "la tenue / llovizna triste humedecía en silencio / de las desiertas calles las baldosas, / 
mientras en los espacios resonaban / las campanas con lentas vibraciones" (Castro 1993: 2, 514).

En un tono similar de aflicción, pesimismo y cierta sensación de cansancio vital parecen orientarse los comentarios sobre edificios simbólicos compostelanos. Se presentan unas descripciones aderezadas con epítetos del tipo "airosa" y "muda" puerta del Colegio de Fonseca", la arquitectura del Hospital Real ${ }^{8}$ se dibuja "altiva" en el espacio, e incluso califica la Catedral de "mole gigantesca". Fonseca le mostró "sus estatuas y relieves / primorosos, encanto del artista" (Castro 1993: 2, 514) y percibió el "gran Hospital, la incomparable / obra del genio, ante mis tristes ojos" (Castro 1993: 2, 514-515).

La poeta continúa su recorrido aludiendo a otros espacios compostelanos implícitos pero notoriamente reconocibles. Así, observa "del Cebedeo la celeste imagen, / como el alma del mártir, blanca y bella, / y vencedora en su caballo airoso; / que galopando en triunfo rasga el aire" (Castro 1993: 2, 515), es decir, la imagen ecuestre del apóstol Santiago que se encuentra en el friso del Palacio de Raxoi, actual sede del Ayuntamiento de Compostela en la plaza del Obradoiro.

También vuelve su mirada al actual Arco de Palacio y al vestigio del arroyo que hoy se puede intuir en un pequeño enrejado bajo el muro del Palacio Arzobispal: "Y bajo el arco oscuro, en donde eterno / del oculto torrente el rumor suena" (Castro 1993: 2, 515).

Y la escritora menciona en un momento de su trayecto lírico que "Atrás quedaba aquella calle adusta, / camino de los frailes y los muertos, / siempre vacía y misteriosa siempre, / con sus manchas de sombra gigantescas" (Castro 1993: 2, 515). Esa calle referida se corresponde con la actual Val de Deus, por lo tanto, el sujeto lírico estaría ubicado en la confluencia de ésta con la calle San Francisco, dispuesto a continuar su camino por la Costa Vella hasta llegar al lugar en el que se encuentra la imagen de Santa Escolástica, es decir, en la iglesia del antiguo monasterio de San Martiño Pinario.

\footnotetext{
7 Frente a este edificio simbólico estuvo la consulta del doctor Maximino Teijeiro, amigo y uno de los médicos de Rosalía de Castro. Con el tiempo, este lugar volvería a estar relacionado con la escritora, puesto que el 29 de diciembre de 1995 se llevó a cabo el acto de presentación pública de la actual Fundación Rosalía de Castro.

8 Se trata de un lugar biográfico imprescindible, al ser bautizada aquí Rosalía de Castro el 24 de febrero de 1837. En la actualidad es el Hostal de los Reyes Católicos, ubicado en uno de los laterales de la plaza del Obradoiro.
} 


\section{Visión antagonista y periférica. Rosalía y sus refugios limítrofes}

Como contraste al espacio que se ajusta al distrito más antiguo de la ciudad, a ese perímetro que rodea y define un núcleo receptor $y$, posteriormente, emisor de un conceptuado sentir pesimista, coexiste un dominio espacial circundante que se caracteriza por una imaginada calidad dúctil de las arquitecturas que se fusionan con el paisaje más rural.

Los espacios más apartados de la Compostella más severa, aquellos que conservan abundante vegetación, rodeados de una atmósfera de silencio y con el encanto de la estética de lo campestre son, sin lugar a dudas, preferentes para la escritora.

Además del cariz de predilección por integrar la esencia de lo rústico y la necesidad de lo arbóreo en el universo rosaliano, la presencia de este micro dominio compostelano estaría desvelando la constante temática, sobre todo lírica, de la búsqueda de intemporalidad a través del espacio. O dicho de otra forma, respondería al continuo conflicto subjetivo entre la percepción del paso del tiempo y el presente del sujeto lírico, tratando de refugiarse en aquella dimensión lo más próxima posible a lo indefinido para huir de la atormentada sensación del tempus fugit.

La escritora compostelana deja claros indicios, tanto en su prosa como en su lírica, de la simpatía que le suscita cualquier emplazamiento boscoso. Así a todo, las opiniones personales conservadas sobre algún lugar concreto son muy escasas, por lo que convendría calibrarlas al máximo en tanto y cuanto resultan ser portadoras de información esencial.

En el caso del micro espacio compostelano San Lourenzo ${ }^{9}$ no da pie a muchas dudas el extracto de una carta que Rosalía remitió a su esposo y en la que manifiesta la atracción que sentía por este espacio:

Ayer fui a paseo con Peregrina Compañel y con Tomás, y entramos en San Lorenzo. Excuso decirte cuánto me acordaría de ti. Vi aquel patio plantado de bojes con aquella fuente profunda y aquella virgen de piedra, todo lo cual me ha dejado encantada. iQué silencio tan inmenso! iY tú nunca has querido llevarme allí! De buena gana hubiera pagado una habitación en San Lorenzo para poder escribir en

9 Este nombre puede referirse tanto al monasterio como al bosque de los alrededores. El monasterio fue fundado por el obispo zamorano Martín Arias en 1216. Tras varias concesiones, los títulos de propiedad, tanto del monasterio como del bosque que le rodea, pasaron a manos de los condes de Altamira, casa nobiliaria que desde finales del siglo XIV había cedido el usufructo a la orden franciscana. Ya en la segunda mitad del siglo XIX, con las exclaustraciones, el monasterio cambió su función religiosa para pasar a tener un uso civil de palacio y custodiado por la casa de Altamira. 
aquel claustro. Es imposible que no saliese una cosa buena. En el claustro de Conjo no se retrata un olvido tan completo como en el de San Lorenzo. No parece que han pasado por aquel convento treinta años de olvido, sino treinta siglos. (Castro 1993: 2, 607)

Rosalía en el poema "iAdiós!" de Follas novas se refiere a este espacio como "San Lourenzo, o escondido, cal un niño antre as ramas" (Castro 1993: 2, 289), por lo tanto, incluyéndolo en la enumeración de los diversos sitios compostelanos de los que la voz lírica se despide y en donde el silencio parece que se hace dueño de las arquitecturas nacidas al pie de la vegetación.

También le dedica a este lugar el poema "San Lourenzo" de Follas novas. Es en la segunda parte de esta composición en la que hay una nítida referencia a la propia historicidad de Rosalía de Castro, al aludir al cambio de funciones llevado a cabo en la arquitectura, "i o vello convento un pazo" (Castro 1993: 2, 402). A través de la pregunta retórica "¿Onde estaba o sagrado retiro?" (Castro 1993: 2, 402), el sujeto lírico refleja el asombro que le causa la circunstancia de no encontrar el ansiado refugio que había sido para la poeta. Y finalmente, como le ocurre otras veces, decide huir: "e máis que nunca abatida / fuxín!" (Castro 1993: 2, 402).

Por su parte, el lugar Conxo ${ }^{10}$ habría que incluirlo también en el grupo de espacios predilectos de Rosalía de Castro. En una carta remitida a su marido exponía lo siguiente:

Anteayer fui a Conjo y nos enseñaron el Cristo. Me ha gustado muchísimo el rostro, y una Virgen de los Dolores que hay allí, también me pareció buena, aunque era ya algo noche y no la pude ver bien. El Cristo nos lo enseñaron con luz. Yendo a pasear hacia allí, entramos después con unos señores y nos aprovechamos de la ocasión. iY el bosque, qué hermosísimo estaba! Era materialmente el suelo un mar de hojas secas. (Castro 1993: 2, 606)

Como ya se tiene dicho sobre Conxo, el paisaje en el que se enclava el monasterio sirve para la meditación inspirada por ese rudo

${ }^{10}$ Como en el caso anterior alude tanto al convento como al bosque. En la época de Rosalía de Castro, Conxo era una aldea cercana a Santiago de Compostela. En 1925 fue cuando se produjo la anexión de este lugar a la ciudad compostelana, tal y como está en la actualidad. La antigua iglesia de Conxo fue edificada en el siglo XII, y tiempo después pasó a tener una función conventual, ocupando esta arquitectura las monjas de la Orden de San Benito, a las que se les atribuye un origen galo. En el siglo XIV la propiedad de este convento pasó a manos de los frailes mercedarios, quienes lo cedieron a la mitra compostelana, aunque ellos siguieron ocupando este espacio incluso en la época de las exclaustraciones. En 1885 el arzobispo compostelano Miguel Payá y Rico accedió a crear en este lugar el primer centro de salud mental de Galicia. Posteriormente fue adquirido por la Diputación de A Coruña en 1969 y se hizo la transferencia al Servicio Gallego de Salud en 1993. 
e involuntario rompimiento entre el ánimo ulcerado y los placeres mundanos (Neira de Mosquera 2000: 138). Quizás, por ello, este punto espacial resulta ser, entre otros, un auténtico y privilegiado lugar rosaliano preferencial en todas y cada una de sus manifestaciones posibles. Su aparición en las obras literarias suele bascular entre ser una referencia al ex convento y su claustro, por ejemplo, en el poema "iAdiós!" de Follas novas, "Conxo, o do craustro triste i as soedades prácidas" (Castro 1993: 2, 289), bien por ser una alusión al bosque de los alrededores, dominio espacial que ya se puede intuir en descripciones concretas de las novelas Flavio y en El primer loco.

Es tal vez a través de las palabras iniciales de la novela El primer loco como nos podemos hacer una idea global del valor que este poético monasterio y el bosque que le rodea llegan a tener y que conocemos por medio del desdoblamiento de la escritora en la (re)creación del personaje principal:

-iYa puedo respirar libremente... ya me encuentro en mi verdadera atmósfera! Sólo aquí, en este lugar de mis predilecciones, en mi quinta abacial, tan llena de encantos y de misterio, puedo calmar en parte la inquietud que me devora el alma. [...]

Adoro de la manera más pagana los altos castaños y los añosos robles y encinas del bosque, bajo cuyas ramas suelo vagar día y noche con el recogimiento con que podría hacerlo antiguo druida, cuando el astro nocturno estaba en su plenilunio, y amo este claustro y profeso a estos arcos, a estas plantas y piedras, el mismo apego que el campesino tiene a su terruño o a la casa en donde ha nacido, se ha criado. (Castro 1993: 2, 675-676)

En relación con esta novela, la fuente de inspiración argumental habría que buscarla en el desarrollo de un largo proceso de debate que tomó fuerza en 1882, un año después de publicar Rosalía El primer loco. Desde 1862 la condesa de Espoz y Mina defendía la iniciativa de transformar el convento de Conxo en un centro en el que albergar a los enfermos mentales. No obstante, la fuerte disputa sobre las competencias a este respecto la llevaron a cabo la jerarquía de la Iglesia católica y la Diputación de A Coruña. En el transcurso de esta polémica se llegó a tal punto que incluso se filtraron noticias a la prensa de la época sobre algún hecho escandaloso, como resultó ser la acusación pública hecha a los mercedarios que ocupaban el edificio de haber realizado talas de árboles del bosque y de vender la madera al mejor postor.

Rosalía de Castro no se mantuvo ajena a estos abusos y denunció literariamente este tipo de actos. En el poema "iJamás lo olvidaré...! De asombro llena" de En las orillas del Sar es contundente en esta cuestión, tanto en la forma como en el fondo: "Profanación sin nombre", "inunca!, inunca! / con su acerado filo osada pudo / el 
hacha penetrar, ni con certero / y rudo golpe derribar en tierra", "Y sin embargo... / inada allí quedó en pie" (Castro 1993: 2, 482-483).

Bastante cercano a Conxo se encuentra el lugar Vidán, nombrado por la escritora como "Vidán alegre, moíños e hondanadas" (Castro 1993: 2, 289), espacio emblemático en el cosmos literario rosaliano porque aquí se juntan los ríos Sar y Sarela, "cubertos de enramada" (Castro 1993: 2, 289), para continuar su trayecto hacia Padrón.

Otro microespacio compostelano esencial es San Domingos de Bonaval ${ }^{11}$, al que la escritora alude con el nombre castellanizado Santo Domingo. De nuevo, es en el poema "iAdiós!" de Follas novas en el que se incluye una patente referencia biográfica, y no es otra que el recuerdo de sus seres queridos y que reposan en el cementerio: "Santo Domingo, en donde canto eu quixen descansa" (Castro 1993: 2, 289).

Muy relacionada con lo anterior estaría también la alusión a la calle de las Trompas que se registra en el poema "Sin terra" de Follas novas, espacio por el que pasaban los cortejos fúnebres que se dirigían al cementerio de Bonaval hasta 1884, momento en el que la Dirección General de Beneficencia y Sanidad lo clausuró. Esta composición parece reflejar un dramático momento lírico extraído de su propia biografía. Tras mandar callar a los vientos nocturnos, la voz lírica continúa pidiendo silencio, "que alá por cabo das Trompas / quero oír quen chega" (Castro 1993: 2, 346), lo que, a su vez, estaría expresando una relación especial de sintonía entre la poeta y la naturaleza, algo que, en la escritora que nos ocupa, se produce en espacios definidos por unos rasgos muy determinados.

Y como si de una concatenación espacial se tratase, esta calle de las Trompas es uno de los accesos para llegar al lugar Belvís y al que también se alude en los versos de ausencia(s) de la composición "iAdiós!" de Follas novas: "Balvis, para min sempre o das fondas lembranzas" (Castro 1993: 2, 289).

${ }^{11}$ Este dominio espacial incluye varios referentes tópicos. El convento fue fundado por Domingo de Guzmán a comienzos del siglo XIII, y desde el siglo XIV tuvo el patrocinio de la casa nobiliaria de Altamira. Con las exclaustraciones, la iglesia que formaba parte del conjunto arquitectónico dejó de estar abierta al culto y pasó a ser propiedad municipal. También se refiere al terreno aledaño al edificio y que fue el antiguo cementerio municipal, en donde reposan los restos de la madre y de dos de los hijos de la escritora. Y en la conocida como capilla de la Visitación se encuentra el Panteón de Gallegos Ilustres, espacio que fue inaugurado precisamente en 1891 con el traslado de los restos mortales de Rosalía de Castro. 


\section{Conclusión}

Tal y como se había proyectado al inicio de este artículo, semeja oportuno realizar alguna anotación acerca de los resultados deductivos obtenidos en referencia a la interacción entre la escritora y Santiago de Compostela.

En primer lugar, cabe la posibilidad de interpretar algunos momentos literarios de Rosalía a través de un prisma renacentista -si se nos permite esta licencia semántica, entendida en su sentido general y usada con cierta elasticidad dentro del contexto de este artículo-, en cuanto que la escritora estaría buscando continuamente un espacio idealizado en base al aurea aetas, o si se prefiere, próximo a una interpretación del beatus ille. Así, el significado del concepto Santiago de Compostela estaría diluyéndose para pasar a ser una nomenclatura de entidad espacial superior y de la que la escritora quiere estar alejada, acaso huir de ella. A la poeta le interesaría encontrar respuestas al ubi sunt? y desearía no percibir sensorialmente el atormentado tempus fugit, de ahí que acabe refugiándose en su locus amoenus, o más bien habría que decir loci amoeni, es decir, en aquellos microespacios dentro de la ciudad pero alejados del núcleo de la Catedral y el significado que ésta parece tener para ella.

En segundo lugar, las reflexiones anteriores nos estarían encauzando a percibir, a través del concepto espacial compostelano, aquellas secuencias de la obra literaria rosaliana ubicadas dentro de este espacio desde un enfoque de medievalismo artístico igualmente, empleamos esta nomenclatura en un sentido general y aplicada al tema tratado en estas líneas- bajo una necesaria praxis analéptica. Tanto la poeta como la prosista serían víctimas de una visión estética y ética de signo medieval. En el caso del sujeto lírico, es esta percepción la que le estaría originando un incontrolable desasosiego ante la vida, siendo el recinto de la Catedral, y más concretamente el Pórtico de la Gloria, el microespacio inductor a la huida espacial y a la evasión cronológica de la poeta.

Por último, no habría que descartar otra posible ruta interpretativa de la interacción entre la escritora y la ciudad compostelana en base al concepto histórico-religioso-mítico de la llegada de los restos del Apóstol Santiago a la ciudad que hoy lleva su nombre. Partiendo de la relación biográfica con el lugar Padrón, podría construirse un imaginado itinerario rosaliano cronotópico en base a dos conceptos históricos del lugar y del propio topónimo: un recinto espacial preapostólico y un distrito (pos)apostólico. 
En cuanto al primero, estaríamos ante el mítico espacio del Libredón, frondoso ${ }^{12}$ bosque de árboles autóctonos situado en el extremo occidental de la comarca natural de A Mahía -en la que se inscribe Padrón, entre otros lugares-. Si se le aplica el concepto de druida a la escritora, entonces cabe la posibilidad de llevar a cabo unas (re)lecturas de sus obras literarias orientadas a reconocer el valor que lo profano adquiere a través de determinados locativos. Así, acudir a los bosques sagrados de San Lourenzo o de Conxo podría interpretarse como un sinónimo de retrospección espacial idealizada de base celta y animista, por lo tanto, un estadio del origen del lugar que conocemos como Santiago de Compostela y de demostrable preferencia para la escritora, según hemos visto a lo largo de estas líneas.

Por su parte, el dominio espacial que, poco a poco, se fue transformando a raíz del hallazgo de los restos atribuidos al Apóstol Santiago desde el siglo IX y que reconocemos en el término Compostella ${ }^{13}$, semeja ajustarse a esa otra fase (pos)jacobea. Acaso, leer a Rosalía desde esta posición podría revelar alguna solución para comprender parte del conflicto dialogado con el espacio más severo y sepulcral y que aparece como una constante tanto en su prosa como en su lírica.

Por último, conviene destacar que existe un acentuado grado de identificación entre las geografías biográfica y literaria de Rosalía de Castro. Sería recomendable hacer una lectura del espacio de Santiago de Compostela reflejado en el dominio literario como un elemento funcional en el que se integran partes indispensables de la propia biografía de la escritora, algo que, por otra parte, no es exclusivo de esta geografía gallega y que sucede en otros casos geográficos puntuales, como por ejemplo en la interacción entre la escritora y la ciudad de Madrid (vid. García Vega 2010b).

De esta forma, las continuas referencias geográficas compostelanas podrían ser consideradas como substratos insustituibles a través de los que estarían creciendo muchos de los versos más intimistas y también abundantes ambientaciones en prosa y que permitirían comprobar o intuir episodios biográficos de la escritora.

\footnotetext{
${ }^{12}$ La tradición recoge que el lugar donde aparecieron los restos del Apóstol se conocía con el nombre de burgo de los tamariscos. El tamarisco o tamariz es un arbusto común en las orillas de los ríos. Desde esta perspectiva, habría que considerar que el lugar compostelano de San Fiz Solovio pudo haber sido un tarayal. Estaríamos ante un dominio espacial claramente alusivo a la flora autóctona.

${ }^{13}$ Es imposible referir aquí la cantidad ingente de hipótesis etimológicas al respecto. Señalamos brevemente las tres más manejadas: bien 'campus stellae', por señalar una estrella el lugar exacto del enterramiento de los restos apostólicos, bien la traducción de 'bien compuesta o bien hecha' según se recoge en el recientemente desaparecido Códex Calixtinus, bien 'compositum tellus' que remite al término cementerio.
} 


\section{Bibliografía}

CASTRO, Rosalía de (1993): Obras completas de Rosalía de Castro. Edición de Marina Mayoral. Madrid: Turner, 2 vols.

GARCÍA VEGA, Lucía (2002): "'Padrón y las inundaciones': ¿tres versións dun artigo costumista?". Revista de Estudios Rosalianos, núm. 2, pp. 37-42.

- (2010a): Os lugares na vida e na obra de Rosalía de Castro: análise literaria [en línea]. Tesis doctoral de la Universidad Complutense de Madrid, Facultad de Filología, Departamento de Filología Románica, Eslava y Lingüística General, leída el 15 de enero de 2010. Madrid: Eprints Complutense, 8 de noviembre de 2010. En: http://eprints.ucm.es/11103.

- (2010b): "Rosalía de Castro e Madrid. Análise literaria dos lugares na novela El caballero de las botas azules (1867)". Moenia, núm. 16, pp. $195-245$.

LA ÉPOCA (1888): "Correo de provincias". La Época, Madrid, 22/01/1888.

NEIRA DE MOSQUERA, Antonio (2000): Monografías de Santiago (1850). Santiago de Compostela: Ara Solís-Consorcio de Santiago.

TORRENTE BALLESTER, Gonzalo (1990): Compostela y su ángel. Barcelona: Destino. 